\title{
Fabrication of nanostructured silicon carbide from rice husks and its photoluminescence properties
}

\author{
Jin LI, Takashi SHIRAI and Masayoshi FUJI \\ Advanced Ceramics Research Center, Nagoya Institute of Technology, \\ Crystal Plaza 4th Floor, 3-101-1 Hommachi, Tajimi, Gifu 507-0033, Japan
}

\begin{abstract}
Nanostructured silicon carbide ( $\mathrm{SiC}$ ) particles and whiskers have been fabricated by pyrolysis of rice husks (RHs) in argon atmosphere. The results revealed that a complete carbothermal reduction of silica was achieved at $1600^{\circ} \mathrm{C}$ for $2 \mathrm{~h}$ and the final product was $\beta$-SiC. The $\beta$-SiC obtained on the bodies of pyrolyzed rice husks (PRHs) was mainly particles having diameters of $100-200 \mathrm{~nm}$ and the wool-like product formed on the inner walls of the graphite crucible was $\beta$-SiC whiskers with diameter of around $170 \mathrm{~nm}$ and tens of micrometers in length. Compared to bulk $\beta$-SiC, down-shifts and asymmetric broadening were observed on both transverse optical (TO) and longitudinal optical (LO) phonon peak in Raman scattering spectra of the nanostructured SiC. The photoluminescence (PL) spectra revealed that the nanostructured $\beta$-SiC, especially the $\beta$-SiC whiskers, showed excellent blue light emission property. The PL emission peak was considerable blue-shifted relative to that for the bulk $\beta$-SiC.
\end{abstract}

(C2012 The Ceramic Society of Japan. All rights reserved.

Key-words : Rice husks, $\beta$-SiC, Particles, Whiskers, Blue light emission

[Received April 23, 2012; Accepted May 28, 2012]

Recently, the photoluminescence properties of $\mathrm{SiC}$ have received considerable attention. Compared with bulk crystal $\mathrm{SiC}, \mathrm{SiC}$ nanostructures show more excellent optical performance because of their low dimensionality, quantum confinement and shape effects. ${ }^{1)-3)}$ Up to now, much effort has been devoted to fabricate various kinds of $\mathrm{SiC}$ nanostructures with special optical properties. For example, Xi et al. synthesized $\beta$-SiC nanorods, nanoneedles by a magnesium-catalyzed co-reduction route, displaying excellent and shape-dependent optical properties. ${ }^{4)}$ $\mathrm{Wu}$ et al. synthesized twinned zigzag $\mathrm{SiC}$ nanoneedles with $\mathrm{SiC}$ nanoparticles aggregates as byproducts via silicon evaporation onto multiwall carbon nanotubes and this kind of nanostructured $\mathrm{SiC}$ showed considerable blue shifts of multi-PL peaks relative to the bulk $\beta$-SiC. ${ }^{5)}$ Niu et al. employed thermal evaporation of $\mathrm{ZnS}$ and carbon on silicon wafer to produce $\beta$-SiC nanowires arrays and show a blue emission luminescence at $430 \mathrm{~nm}^{6}{ }^{6} \mathrm{Li}$ et al. synthesized $\beta$-SiC nanospheres and nanowires by a metal coreduction method, showing a wide blue emission luminescence centered at $443 \mathrm{~nm} .{ }^{7)}$ Even though they were basically successful, most of them involve complex procedures, extra metal catalyst or expensive precursors.

As we known, huge amounts of rice husks (RHs) are produced annually in the world as an agricultural byproduct of rice threshing. RHs have been proved to be an economical and promising raw material for producing $\mathrm{SiC}$, due to high surface area and intimate contact available for carbon and silica. ${ }^{8)-12)}$ However, few literatures are accessible about optical properties of $\mathrm{SiC}$ that fabricated by pyrolysis of RHs. In this study, nanostructured $\beta$-SiC particles and whiskers were prepared by using RHs as precursors. The microstructure and optical properties of the $\beta$-SiC were studied.

RHs were collected from a local rice mill factory of Japan. The RHs are composed of about 75 mass \% organic constituents

Corresponding author: M. Fuji; E-mail: fuji@nitech.ac.jp (hemicelluloses, cellulose and lignin), 5 mass $\%$ water, 18 mass $\%$ $\mathrm{SiO}_{2}$ and 2 mass $\%$ other impurities $\left(0.88\right.$ mass $\% \mathrm{~K}_{2} \mathrm{O}, 0.46$ mass $\% \mathrm{SO}_{3}, 0.31$ mass $\% \mathrm{Al}_{2} \mathrm{O}_{3}, 0.23$ mass $\% \mathrm{CaO}, 0.07$ mass $\%$ $\mathrm{P}_{2} \mathrm{O}_{5}, 0.04$ mass $\% \mathrm{MnO}$ and 0.01 mass $\% \mathrm{Fe}_{2} \mathrm{O}_{3}$ ). High-purity argon (>99.999\%) gas was used as the shielding gas in this work. In a typical experimental procedure, $6 \mathrm{~g}$ of RHs placed in an airtight graphite crucible $(80 \times 80 \times 10 \mathrm{~mm})$ were put into an electric furnace. After evacuating to $\sim 5 \mathrm{~Pa}$, high-purity argon gas was introduced to the furnace at constant flow rate of $2 \mathrm{~L} / \mathrm{min}$ and maintained at a positive pressure of $\sim 50 \mathrm{kPa}$ throughout the whole following experiment. The furnace was firstly heated to $1000^{\circ} \mathrm{C}$ at a rate of $15^{\circ} \mathrm{C} / \mathrm{min}$, then up to 1500 and $1600^{\circ} \mathrm{C}$ respectively at a rate of $10^{\circ} \mathrm{C} / \mathrm{min}$. After maintained at target temperature for $2 \mathrm{~h}$, the furnace was cooled down to room temperature naturally and pyrolyzed rice husks (PRHs) were received. Then the PRHs were calcined in air at $600^{\circ} \mathrm{C}$ for $3 \mathrm{~h}$ to remove the residual carbon and leached by dilute $\mathrm{HF}$ solution to remove the impurities. The final product was denoted as SiCPRHs. On the other hand, wool-like products with light green color formed on the inner walls of graphite crucible, which were also collected without any further treatment and denoted as SiC-crucible. The crystal structures of the samples were characterized by X-ray diffraction patterns (XRD, Rigaku, UltimaIV). Morphology observation and microstructure analysis were performed by scanning electron microscopy (SEM, JEOL, JSM7600F) and Transmission electron microscopy (TEM, JEOL, JEM2010). Raman scattering spectra was produced by a microRaman spectrometer (JASCO, NRS-3100) using $532 \mathrm{~nm}$ excitation wavelength at room temperature. The photoluminescence (PL) spectra were performed in a spectrofluorometer (JASCO, P-6500) with a Xe lamp at room temperature.

Figure 1 shows the XRD patterns of the products. Major diffraction peaks at $2 \theta=35.6,41.4,60.0,71.8$ and $75.5^{\circ}$ can be indexed as (111), (200), (220), (311) and (222) reflections of $\beta$-SiC, respectively (JCPDS Card No. 29-1129). The small peak 


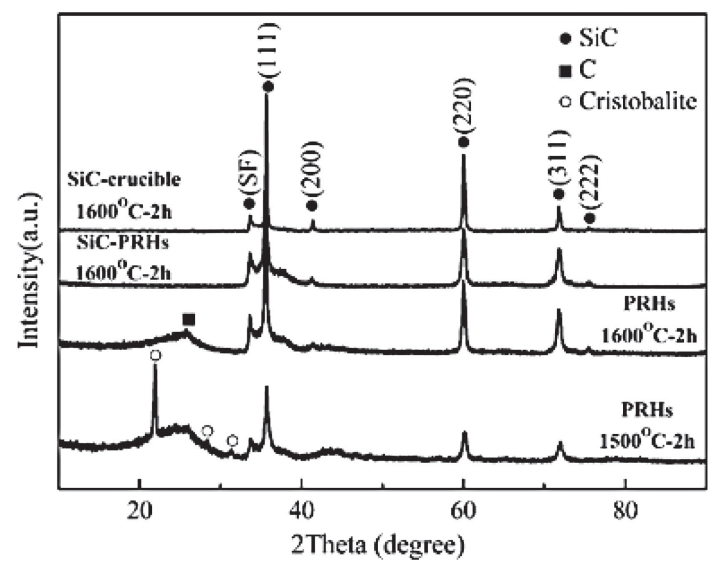

Fig. 1. XRD patterns of the products.
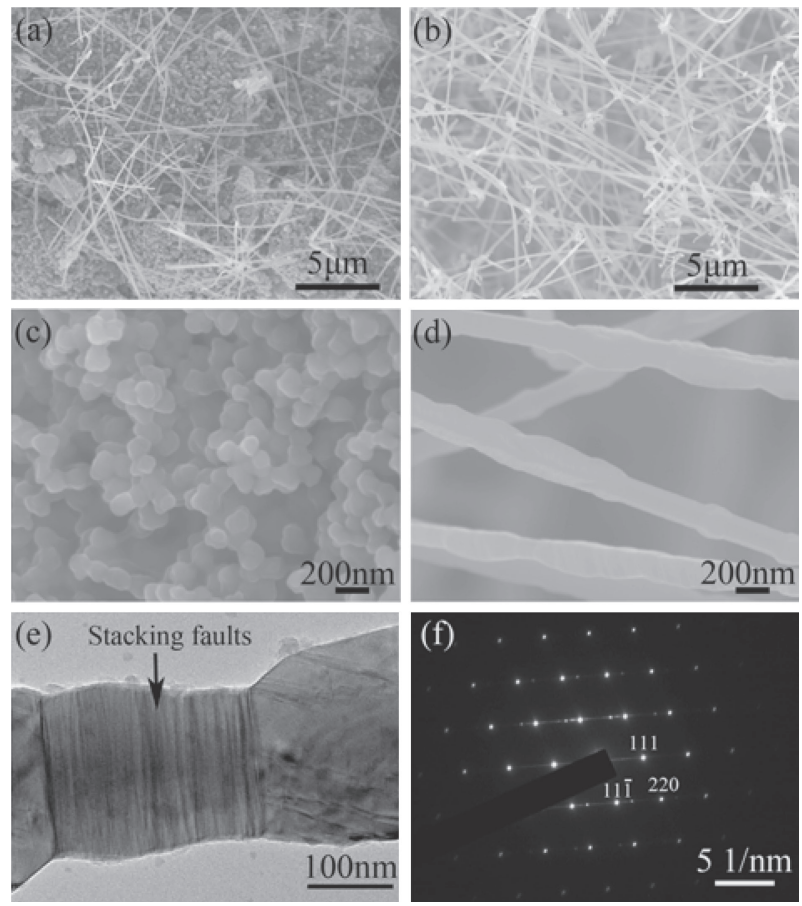

Fig. 2. SEM images of the products obtained at $1600^{\circ} \mathrm{C}$ for $2 \mathrm{~h}$ : (a) $\mathrm{SiC}$-PRHs (b) SiC-crucible (c) $\beta$-SiC particles (d) $\beta$-SiC whiskers. (e) TEM image of a typical $\beta$-SiC whisker and (f) its corresponding SAED pattern.

ahead of the most intensive peak (111) marked with SF is attributed to the stacking faults of $\beta$-SiC. ${ }^{13)}$ Characteristic peaks of cristobalite are found in the XRD pattern of the PRHs obtained at $1500^{\circ} \mathrm{C}$ for $2 \mathrm{~h}$, revealing that the reaction was not completed and unreacted $\mathrm{SiO}_{2}$ crystallized to cristobalite. The diffraction peak at around $26^{\circ}$ in the XRD pattern of the PRHs obtained at $1600^{\circ} \mathrm{C}$ for $2 \mathrm{~h}$ confirms the existence of residual carbon and no noticeable peaks of $\mathrm{SiO}_{2}$ can be detected, indicating a complete carbothermal reduction. Thus, the products obtained at $1600^{\circ} \mathrm{C}$ for $2 \mathrm{~h}$ were selected for further study. Only characteristic peaks of $\beta$-SiC are observed in the XRD patterns of SiC-PRHs and SiC-crucible, revealing that pure $\beta$-SiC was obtained.

As can be seen in Figs. 2(a) and 2(b), the SiC-PRHs is mainly composed of particles with small amount of whiskers dispersing on surface, whereas the $\mathrm{SiC}$-crucible is composed of $\beta$-SiC whiskers having several to tens of micrometers in length.

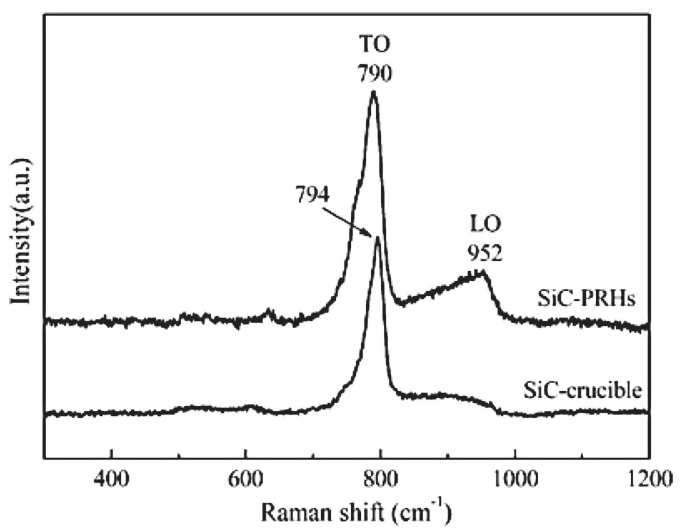

Fig. 3. Raman spectra of the $\beta$-SiC obtained at $1600^{\circ} \mathrm{C}$ for $2 \mathrm{~h}$.

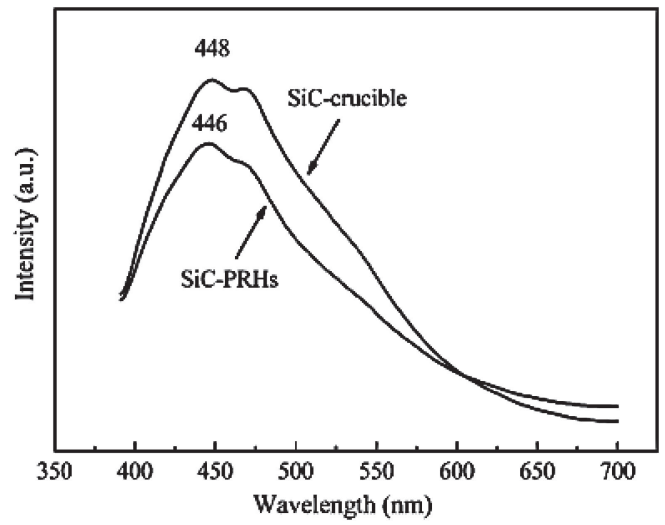

Fig. 4. Photoluminescence (PL) spectra of the $\beta$-SiC obtained at $1600^{\circ} \mathrm{C}$ for $2 \mathrm{~h}$.

Figures 2(c) and 2(d) exhibit the morphology of the $\beta$-SiC particles and whiskers. The $\beta$-SiC particles have diameters of $100-200 \mathrm{~nm}$ and the whiskers show diameter of around $170 \mathrm{~nm}$. Figure 2(e) shows the TEM image of a typical whisker. The stacking faults are valid on the whisker, which is consistent with the result of the XRD pattern. From the SAED pattern of the $\beta$-SiC whisker [Fig. 2(f)], it can be concluded that the $\beta$-SiC whisker has a single crystal structure and grow along the [111] orientation.

Figure 3 displays the typical Raman spectra taken from the $\mathrm{SiC}-\mathrm{PRH}$ and $\mathrm{SiC}$-crucible. As can be seen in the Raman spectrum of the SiC-PRHs, the characteristic peaks at around 790 and $952 \mathrm{~cm}^{-1}$ are attributed to transverse optical (TO) phonon mode and longitudinal optical (LO) phonon mode at $\Gamma$ point of $\beta$-SiC, respectively. Relative to that for bulk $\beta$-SiC, ${ }^{14)}$ the characteristic peak centers are down-shifted by 6 and $20 \mathrm{~cm}^{-1}$, respectively. Furthermore, obvious asymmetric broadening was observed on both of the peaks, especially on peak of LO phonon mode. From the Raman spectrum of SiC-crucible, an intense peak of TO phonon mode was detected at $794 \mathrm{~cm}^{-1}$. However, no obvious peak of LO phonon mode was detected. The unique optical properties exhibited in Raman spectra can be ascribed to the size confinement effects and defects of nanostructured $\beta$-SiC. ${ }^{15), 16)}$

The photoluminescence (PL) properties of the products were investigated at room temperature under excitation wavelength at $367 \mathrm{~nm}$. The PL spectra of the as-obtained $\beta$-SiC are shown in Fig. 4. It can be found that the SiC-PRHs and SiC-crucible display strong blue light emission at 446 and $448 \mathrm{~nm}$, respectively. Compared with that of bulk $\beta$-SiC $(519 \mathrm{~nm}),{ }^{17)}$ the PL 
peak position is considerable blue-shifted, which is attributed to the quantum confinement effect of nanomaterials and involved defects. ${ }^{18)}$ Furthermore, the SiC-crucible shows higher peak intensity, indicating that the $\beta$-SiC whiskers have a better light emission performance than the $\beta$-SiC particles. It is believed that the more excellent light emission property of the $\beta$-SiC whiskers is ascribed to the high length/diameter aspect ratio and large amounts of stacking faults of one-dimensional structure.

In summary, nanosized $\beta$-SiC particles and whiskers have been fabricated by pyrolysis of RHs in this study. The $\beta$-SiC particles have diameters of $100-200 \mathrm{~nm}$ and the $\beta$-SiC whiskers show diameters of around $170 \mathrm{~nm}$ and several to tens of micrometers in length. The nanostructured $\beta$-SiC, especially the $\beta$-SiC whiskers, show excellent blue light emission property.

\section{References}

1) D. H. Feng, Z. Z. Xu, T. Q. Jia, X. X. Li and S. Q. Gong, Phys. Rev. B, 68, 035334 (2003).

2) F. A. Reboredo, L. Pizzagalli and G. Galli, Nano Lett., 4, 801804 (2004).

3) R. Rurali, Phys. Rev. B, 71, 205405 (2005).

4) G. C. Xi, Y. K. Liu, X. Y. Liu, X. Q. Wang and Y. T. Qian, J. Phys. Chem. B, 110, 14172-14178 (2006).

5) R. B. Wu, Y. Pan, G. Y. Yang, M. X. Gao, L. L. Wu, J. J. Chen, R. Zhai and J. Lin, J. Phys. Chem. C, 111, 6233-6237 (2007).
6) J. J. Niu and J. N. Wang, J. Phys. Chem. B, 111, 4368-4373 (2007).

7) P. Li, L. Q. Xu and Y. T. Qian, Cryst. Growth Des., 8, 2431$2436(2008)$

8) R. V. Krishnarao and Y. R. Mahajan, Ceram. Int., 22, 353-358 (1996).

9) R. V. Krishnarao and M. M. Godkhindi, Ceram. Int., 18, 243249 (1992)

10) R. V. Krishnarao, M. M. Godkhindi, M. Chakraborty and P. G. Mukunda, J. Mater. Sci., 29, 2741-2744 (1994).

11) R. V. Krishnarao, M. M. Godkhindi, P. G. Mukunda and M. Chakraborty, J. Am. Ceram. Soc., 74, 2869-2875 (1991).

12) P. Gorthy and G. M. Pudukottah, J. Am. Ceram. Soc., 82 , 1393-1400 (1999).

13) K. Koumoto, S. Takeda, C. H. Pai, T. Sato and H. Yanagida, J. Am. Ceram. Soc., 72, 1985-1987 (1989).

14) S. Nakashima and H. Harima, Phys. Status Solidi A, 162, 3963 (1997).

15) G. W. Meng, Z. Cui, L. D. Zhang and F. Phillipp, J. Cryst. Growth, 209, 801-806 (2000).

16) W. S. Shi, Y. F. Zheng, H. Y. Peng, N. Wang, C. S. Lee and S. T. Lee, J. Am. Ceram. Soc., 83, 3228-3230 (2000).

17) H. W. Shim, K. C. Kim, Y. H. Seo, K. S. Nahm, E.-K. Suh, H. J. Lee and Y. G. Hwang, Appl. Phys. Lett., 70, 1757-1759 (1997).

18) A. P. Alivisatos, Science, 271, 933-937 (1996). 